\title{
Students Learning Problem Solving in Introductory Physics - Forming an Initial Hypothesis of Instructors' Beliefs
}

\author{
Charles Henderson ${ }^{+}$, Kenneth Heller*, Patricia Heller*, Vince H. Kuo*, Edit Yerushalmi ${ }^{\xi}$ \\ ${ }^{+}$Western Michigan University, Kalamazoo, MI \\ *Physics Education Research Group, University of Minnesota, Minneapolis, MN \\ ${ }^{\xi}$ Weizmann Institute, Rehovot, Israel
}

\begin{abstract}
Based on an analysis of structured interviews with 6 research university physics faculty members, this paper presents our initial hypothesis of instructors' beliefs about how their students learn to solve problems in an introductory physics course. The hypothesis shows that these instructors have very general beliefs about the process of student learning that do not include many details about actual learning mechanisms.
\end{abstract}

\section{Introduction}

Many students leave traditional introductory physics courses unable to solve standard test problems. Those that can often do so without an understanding of the physics concepts on which these problems are based. [1] Curriculum developers have focused their efforts on two general ways of improving this situation. Some emphasize directly building students' conceptual knowledge [2-3] while others emphasize developing students' problem-solving skills. [4-6] Although aspects of many of these curricula are reflected in some instructors' practices, seldom are the curricula fully adopted. This lack of full adoption likely reflects a mismatch between the curricula and the beliefs and values of the instructors who must implement the curricula.

In order to begin to understand the beliefs and values of these instructors, we conducted interviews with 6 physics faculty members from a large research university. The purpose of this study was to develop analysis techniques and generate testable hypotheses of physics instructors' beliefs and values about the teaching and learning of problem solving in introductory calculus-based physics. The initial hypotheses resulting from this study will guide further investigations using larger samples.

This is the first of two papers describing this study. This paper will concentrate on our initial hypotheses related to the learning activities these instructors believe students can engage in to learn how to solve physics problems. The second paper
[7] will focus on our initial hypotheses related to teaching activities these instructors believe they can engage in to help students learn how to solve physics problems.

\section{Data Collection}

Data were collected using a semi-structured interview based on concrete instructional artifacts commonly used in physics instruction. [8] All of the artifacts dealt with an introductory physics problem that was given to the instructors to solve prior to the interview. The artifacts used were: three instructor solutions, five student solutions, and three types of problems. They were constructed to span a variety of student and instructor practices.

Each individual interview lasted about 11/2 hours and consisted of four parts. The first three parts of the interview, each dealing with one of the three types of artifacts, started with general questions about how and why the instructor used that type of artifact (e.g., "In what situations do you use instructor solutions?"). The instructor was then asked to compare each artifact to those he actually used (e.g., "Take a look at these three instructor solutions and describe how they are similar or different to the types of solutions you use."). Each part concluded by asking the instructor to reflect on the problem-solving process, as represented in each artifact (e.g., "What aspects/components that you consider important in problem solving are represented in these instructor solutions?"). 


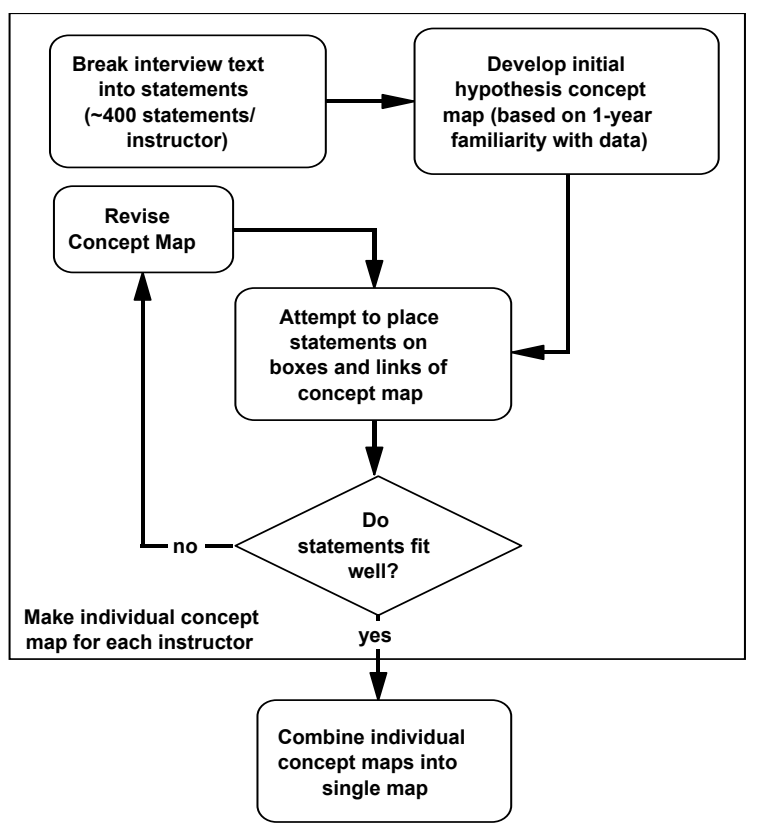

Figure 1: Analysis Procedure

During these three parts the interviewer noted each of the features of the problem-solving process that was mentioned on a separate index card, using the faculty member's words. In the final part of the interview they were asked to sort these cards into categories of their choosing. They were then asked several questions about the categories, including their expectations about student learning of these problem-solving processes by the end of their course. Throughout the interview probing questions were used to encourage the instructors to explain their ideas in as much detail as possible.

The 6 instructors, all male, were randomly selected from approximately 20 physics faculty at a large research university who had recently taught an introductory calculus-based course. The standard mode of instruction for introductory calculus-based physics at this university includes each instructor's implementation of Cooperative Group Problem Solving. [4]

\section{Analysis Technique}

The analysis procedure (see Figure 1) used interview transcripts to develop a multi-layered concept map that described our hypotheses about the way that this group of 6 instructors thought

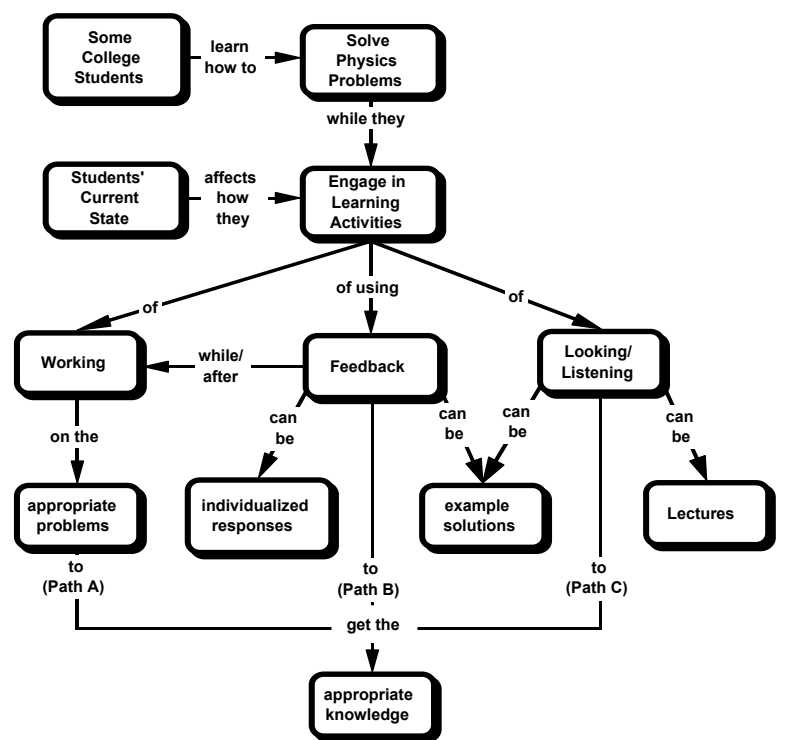

Figure 2: Highest-Level Concept Map Describing Initial Hypotheses about of Instructors' Thinking About the Learning of Problem Solving.

about the teaching and learning of problem solving. [8] Triangulation and expert agreement were used to determine the results. The highest level of this concept map has 18 relevant features and their relationships that are common to all 6 of the instructors. Each of these relevant features, represented by a box on the concept map, is described in detail by a lower-level map that also gives the range of variation among the instructors. Due to space limitations, the lower-level maps will not be presented here; however, the relevant information from these maps will be used in the discussions that follow.

\section{Results: How Do Students Learn How to Solve Problems?}

Twelve of these 18 relevant features are related to the learning of problem solving and are shown in Figure 2. The instructors conceive of three independent types of learning activities, each of which allows some college students to learn how to solve physics problems:

1. Using Feedback while/after working on problems

2. Working on problems

3. Looking/Listening to example problem solutions or lectures 
These three types of learning activities are what we would expect any experienced introductory physics instructor to recognize. More interesting, however, is that the instructors talked about each of these learning activities in up to two distinct levels of detail. In the first level they described general student actions that can lead to learning. In the second level they described specific student actions that can lead to learning. Many of the instructors did not talk about student learning in this second, more specific, level of detail.

Using Feedback. The instructors talked the most about learning activities involving the use of feedback. The defining feature of this type of learning activity is that learning takes place directly from the feedback. All six instructors believed that students could learn how to solve physics problems by working on problems on their own and then looking at the delayed feedback of example problem solutions. They all thought that students should engage in the general activity of comparing their solutions to the example solutions in an effort to analyze their mistakes. However, most instructors believed that most students do not in fact do this. Only one instructor, however, described what, specifically, students should do. He suggested that students should focus on the structure of the problem rather than on the details. Four of the instructors also believed that students learn how to solve physics problems through the general activity of working on problems while receiving real-time feedback. This real-time feedback was typically described as coaching and was thought of as something that the student should initiate by working on problems with other students or coming to office hours to get help from the instructor. None of the instructors gave more details about what specific actions students should perform during this coaching.

Working on problems. The defining feature of this type of learning activity is that learning takes place solely because of the student activity of working problems - no external feedback is required. The instructors frequently referred to this general learning activity as "practicing". Three instructors did not provide any specific details about student actions involved in practicing. The other three described some specific actions. For example, two instructors suggested that the goal of practicing is to generalize certain aspects of the appropriate knowledge from the particular problem that the student is working on. These instructors suggested that students could do this by clarifying to themselves why they are doing each step and not something else.

Looking/Listening. The defining feature of this type of learning activity is that learning takes place without the student needing to work on problems. One instructor did not believe that students can learn how to solve problems without actually working on problems. Another instructor thought that students might be able to learn something without working on problems, but that actually working on problems would be more effective. All five instructors who believed that learning can take place by looking/listening described the general student action of looking/listening to example problem solutions. These are typically problems that the instructor solved on the board during lecture, but can also be written problems from a textbook or other source. Only one instructor described any specific student actions. He said that they should "think about what is going on". Four of these instructors also expressed a belief that students could learn how to solve problems through the general activity of looking/listening to lectures about problem solving techniques or strategies. This lecturing was not described as being attached to a particular problem and no further details were given about what specific actions students should perform.

\section{Discussion}

The initial hypothesis described in this paper is that university instructors think about three distinct ways that students can learn how to solve physics problems. Conventional wisdom might suggest that typical research university instructors would have rather traditional, teacher-centered 


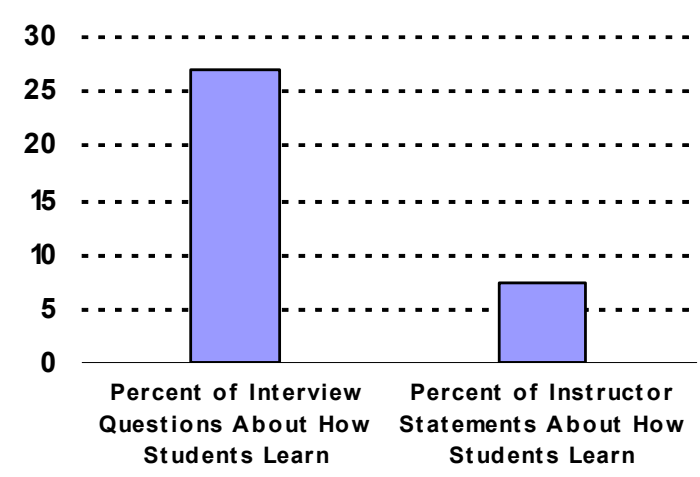

Figure 3: Comparison of questions vs. responses about how students learn.

views of learning -- the most important way that students learn is by coming to lecture and watching the instructor solve problems and discuss problem-solving techniques. However, these six instructors viewed this type of learning activity as the least effective of the three presented. All of the instructors believed that the best way for students to learn how to solve physics problems is by trying to solve physics problems, either with or without external feedback.

This hypothesis can now be tested for a wider range of instructors. If it is confirmed, it would suggest that physics instructors do not avoid curricula that involve active learning (i.e., students working rather than looking/listening) based on their beliefs that these curricula would not help students learn. Some alternative explanations are discussed in the next paper. [7]

A very important feature of these instructors' views of student learning activities is that they described few specific details about what students should do to learn. As Figure 3 shows, although $27 \%$ (7 of 26) of the interview questions asked specifically about actions students should perform to learn, only $7 \%$ ( 28 of 390 , on average) of the statements made by each instructor described such actions. This suggests that these instructors lack an explicit model of the mechanisms by which students learn. In fact, there was little indication that they thought any explicit mechanisms were involved.

If verified using a more extensive sample of instructors, this suggests that curriculum developers need to communicate to instructors in a way that does not require the instructors to believe that specific mechanisms enable students to learn. Alternatively, it may be necessary for faculty to be introduced to the existence and importance of such learning mechanisms.

1 See, for example, review by Maloney, D., Research on problem solving: Physics, in D, Gabel (ed.), Handbook of Research on Science Teaching and Learning, MacMillan, New York, 1994.

${ }^{2}$ McDermott, L.C., Shaffer, P.S., \& the Physics Education Group, Tutorials in Introductory Physics - Preliminary Edition, Prentice Hall, Upper Saddle River, NJ, 1998.

${ }^{3}$ Mazur, E., \& Crouch, C.H., Peer Instruction: Ten years of experience and results, American Journal of Physics, vol. 69, pp. 970-977, 2001.

${ }^{4}$ Heller, P., Keith, R., \& Anderson, S., Teaching problem solving through cooperative grouping. Part 1: Groups versus individual problem solving, American Journal of Physics, vol. 60, pp. 627-636, 1992.

${ }^{5}$ Leonard, W., Dufresne, R., \& Mestre, J., Using qualitative problem-solving strategies to highlight the role of conceptual knowledge in solving problems, American Journal of Physics, vol. 64, pp. 1495-1503, 1996.

${ }^{6}$ Van Heuvelen, A., Learning to think like a physicist: A review of research-based instructional strategies, American Journal of Physics, vol. 59, pp. 891-897, 1991.

${ }^{7}$ Kuo, V. H., Heller, K., Heller, P., Henderson, C., \& Yerushalmi, E. Helping students learn problemsolving - Forming an initial model of instructors' beliefs. Proceedings of the Physics Education Research Conference, Boise, ID, August, 2002.

8 For more details about data collection and analysis, see Henderson, C., Faculty Conceptions About the Teaching and Learning of Problem Solving in Introductory Calculus-Based Physics. Unpublished Doctoral Dissertation, University of Minnesota, 2002. (online: homepages.wmich. edu/ chenders) 